\title{
Gestão por competências: a percepção dos colaboradores de uma cooperativa de crédito
}

\author{
Competence management: \\ the perception of employees of a credit cooperative
}

\begin{abstract}
Resumo
$\mathrm{Na}$ gestão por competências, delinear as características de um perfil ideal para determinada função se apresenta como um grande desafio. Nesse sentido, o presente estudo teve como objetivo identificar quais as competências necessárias para prestar um atendimento de qualidade aos associados. O estudo apresenta delineamento descritivo dos tipos levantamento e análise de dados quantitativa. Para tanto, um questionário foi aplicado aos colaboradores de uma cooperativa de crédito. Com os resultados da pesquisa, foi possível identificar 40 competências relevantes à prestação de um atendimento de qualidade. Além disso, a atitude foi considerada a categoria mais importante pelos colaboradores. Para finalizar, são apontadas recomendações para a realização de novas pesquisas.
\end{abstract}

Palavras-chave: gestão de pessoas, competências, cooperativa de crédito.

\begin{abstract}
In competency management, delineating the characteristics of an ideal profile for a given function presents itself as a major challenge. In this sense, the present study aimed to identify the competencies necessary to provide a quality service to members. The study presents descriptive design of the survey types and quantitative data analysis. To do so, a questionnaire was applied to the employees of a credit cooperative. With the results of the research it was possible to identify 40 relevant competences to provide a quality service. In addition, the attitude was considered the most important category by the employees. Finally, recommendations are made for further research.
\end{abstract}

Keywords: people management, skill, credit cooperative.

Éder Luiz HerbstrithI ${ }^{1}$, Rejane Inês Kieling ${ }^{\text {II }}$

${ }^{\text {I } F a c u l d a d e ~ d e ~ T e c n o l o g i a ~ d o ~ C o o p e r a t i v i s m o ~-E S C O O P, ~ P o r t o A l e g r e / R S . ~}$

${ }^{\text {II }}$ Faculdade de Tecnologia do Cooperativismo -ESCOOP, PortoAlegre/RS. rejanekieling@hotmail.com 


\section{Introdução}

O segmento das cooperativas de crédito representa na atualidade um dos ramos mais dinâmicos do cooperativismo. No território gaúcho existem unidades de atendimento de cooperativas de crédito em praticamente todos os municípios, gerando 9,6 mil empregos diretos e prestando serviços a 1,9 milhão de associados. Importante destacar que, conforme a classificação de risco do Banco Central, os menores níveis de risco de recebimento encontram-se nas categorias $\mathrm{A}, \mathrm{B}$ e $C$, sendo $85,63 \%$ da carteira de crédito das cooperativas distribuídas nestes níveis. (EXPRESSÃO DO COOPERATIVISMO GAÚCHO, 2018).

No que diz respeito às suas características, o cooperativismo de crédito possui particularidades que, inclusive, conflitam com as práticas de mercado do setor no qual está inserido, neste caso, o financeiro. Como exemplo, é possível citar a questão de o cooperativismo não possuir fins lucrativos, mas estar focado na distribuição entre os sócios dos resultados obtidos no exercício, a preocupação com desenvolvimento social e econômico de seus associados e com o ambiente no qual estão inseridos, etc.

Essas características, ao mesmo tempo em que demonstram uma maior complexidade para a gestão do negócio, servem como subsídios para a sustentação de diferenciais estratégicos e concorrenciais. Nesse caso, a gestão por competências se apresenta como uma ferramenta promissora, pois suas características e objetivos principais, de modo geral, comungam com os princípios que regem o cooperativismo. No contexto da presente pesquisa, destaca-se, em primeiro lugar, o princípio voltado a educação cooperativista, pois entende-se que a identidade do cooperativismo deva ser assimilada por meio de ações práticas, no caso em questão, ações que visem permanente melhorias nas competências do quadro funcional da cooperativa e estudada. E, em segundo lugar, o princípio voltado às ações da cooperativa junto à comunidade, pois tem-se presente o compromisso de uma cooperativa de crédito como propulsora do desenvolvimento local.

Partindo deste entendimento, o presente trabalho se propõe a identificar, por meio da percepção dos colaboradores da cooperativa de crédito "Gama", quais competências se fazem necessárias para prestar um atendimento de qualidade aos seus associados. Tendo por objetivo final contribuir ao processo de tomada de decisão da gestão da cooperativa ao apresentar-se como resultados da pesquisa um mapeamento do perfil das competências existentes na cooperativa "Gama".

O primeiro passo para pesquisar e analisar a gestão por competências é compreender o conceito da nomenclatura. Para tanto, buscou-se subsídios em pesquisas acerca da temática, de modo a amparar o presente estudo e elucidar a conceituação apropriada para o termo. Constatou-se que, mesmo nos dias atuais, atribuir um conceito para competências não é uma tarefa simples. Isso se deve à grande quantidade de ênfases e abordagens que acometem o assunto. Não obstante, procurou-se uma aproximação com autores e suas respectivas conceituações, de modo a proporcionar uma visão ampla do significado desse termo, bem como suas possíveis classificações.

A partir de uma breve contextualização da gestão de pessoas na contemporaneidade, delineou-se o cenário que se apresenta para os gestores do setor, tal como seu novo papel no âmago das empresas e os desafios que levam as organizações a buscarem alternativas e ferramentas. Compreende-se que a gestão por competências se apresenta como uma alternativa aos tradicionais modelos de gestão, que, no contexto atual, tornaram-se obsoletos.

A gestão por competências objetiva conciliar o crescimento das organizações com o das pessoas que delas fazem parte. Promover treinamento, desenvolvimento e, ao mesmo tempo, motivar os colaboradores a se autodesenvolverem visando o alcance de competências que sustentarão a estratégia organizacional, conferindo diferenciais estratégicos e, consequentemente, ganhos econômicos, além do ganho social aos colaboradores. 
Surge, assim, a perspectiva do ganho social. Visão defendida por autores que acreditam que a gestão por competências é uma ferramenta completa, exatamente por ser capaz de proporcionar o desenvolvimento econômico da organização e, ao mesmo tempo, trazer ganhos sociais aos colaboradores. Tais ganhos estariam subdivididos em três categorias: pessoal, funcional e comportamental.

Desta forma, no presente estudo, buscou-se identificar, segundo a percepção dos colaboradores da cooperativa de crédito "Gama”, quais as competências necessárias para que eles possam prestar um atendimento de qualidade aos associados. E também promover uma comparação entre as competências elencadas pelos colaboradores com as estabelecidas pela administração da "Gama”, identificando concordâncias, discordâncias.

\section{Revisão Conceitual}

Os estudos sobre competências baseiam-se em duas correntes distintas: uma formada por pesquisadores norte-americanos, pioneiros no estudo do tema, e a outra, por pesquisadores franceses. Segundo Fleury e Fleury (2001), nos Estados Unidos, as discussões acerca do tema tiveram início no ano de 1973, na tentativa do psicólogo e pesquisador norte-americano David McClelland em propor uma alternativa aos tradicionais testes de inteligência e atitude, utilizados para medir o desempenho de estudantes na época. Durante a década de 1980, Richard Boyatzis realiza uma reanálise sobre o assunto, e aborda as competências na perspectiva gerencial, que somados aos estudos de McClelland, tornaram-se referência na literatura americana sobre o assunto.

Na Europa, conforme Fleury e Fleury (2001), os debates acerca do tema também se iniciam em meados da década de 1970, na França, juntamente com o questionamento dos conceitos de qualificação e formação profissional, restringindo-se à área educacional. Com o passar dos anos, as discussões se estenderam ao contexto profissional e, no princípio dos anos 1990, é que o tema emerge com grande força na literatura francesa, destacando-se, como principais autores, Philippe Zarifian e Le Bortef.

Esses autores destacam ainda que, no Brasil, os debates só tiveram início na esfera acadêmica durante a década de 1990, utilizando, como base, o princípio da literatura norte-americana, mas, logo, passou-se a utilizar também a literatura francesa, enriquecendo, deste modo, a conceituação e dando origens a novos enfoques (FLEURY; FLEURY, 2001).

Mesmo não havendo consenso sobre o conceito exato para o termo competência, todos que se propõem a discutir o tema concordam que não existe competência sem ação. São as características, requisitos, conhecimentos, habilidades ou aptidões colocadas em prática, produzindo efeitos e resultados, de soluções de problemas. (RESENDE, 2000). Para Fleury e Fleury (2008, p. 187), "os conhecimentos e o know how não adquirem status de competência a não ser que sejam comunicados e utilizados". Para Hipólito (2001), a competência só é demonstrada no momento em que o indivíduo se mobiliza e coloca em prática conhecimentos em diferentes situações. Ao abordarem tais aspectos, esses autores constituíram um conceito amplo e atual, resultando em um significado mais completo para competência.

\subsection{Competências individuais e coletivas}

As discussões sobre competências a partir da dimensão individual não são recentes, e têm sido muito discutidas, especialmente por autores norte-americanos, que analisam o tema de forma bastante direta e objetiva. Por outro lado, os franceses buscam elementos na sociologia e na economia do trabalho, de modo a ampliar sua dimensão (RUAS, 2003).

Ainda, Ruas (2005) sintetiza a formação de competências individuais nas capacidades (conhecimento, habilidades e atitudes) já desenvolvidas em situações anteriores (experiências) ou 
que podem vir a ser ampliadas por meio de treinamentos específicos ou no decorrer do desempenho do próprio trabalho.

Para Fleury e Fleury (2008), as competências individuais categorizam-se em três blocos: competência de negócio, relacionadas ao entendimento do negócio, como se relacionar com o mercado, clientes, competidores e ambiente político e social; competências técnico-profissionais: direcionadas a áreas específicas de atuação; competências utilizadas para interação social: compreendem a capacidade dos indivíduos de se relacionarem.

É possível verificar que Ruas e Fleury e Fleury, ao descreverem as competências individuais, convergem no que diz respeito a sua formação. Segundo esses autores, tais competências estão alicerçadas em três dimensões. Apesar de não possuírem as mesmas nomenclaturas, após uma breve análise, é possível, facilmente, constatar que as chamadas dimensões se fundamentam em conhecimentos, habilidades e atitudes. A Figura 1 ilustra a formação da competência por meio da conexão de conhecimentos, habilidades e atitudes.

Figura 1- Dimensões das competências

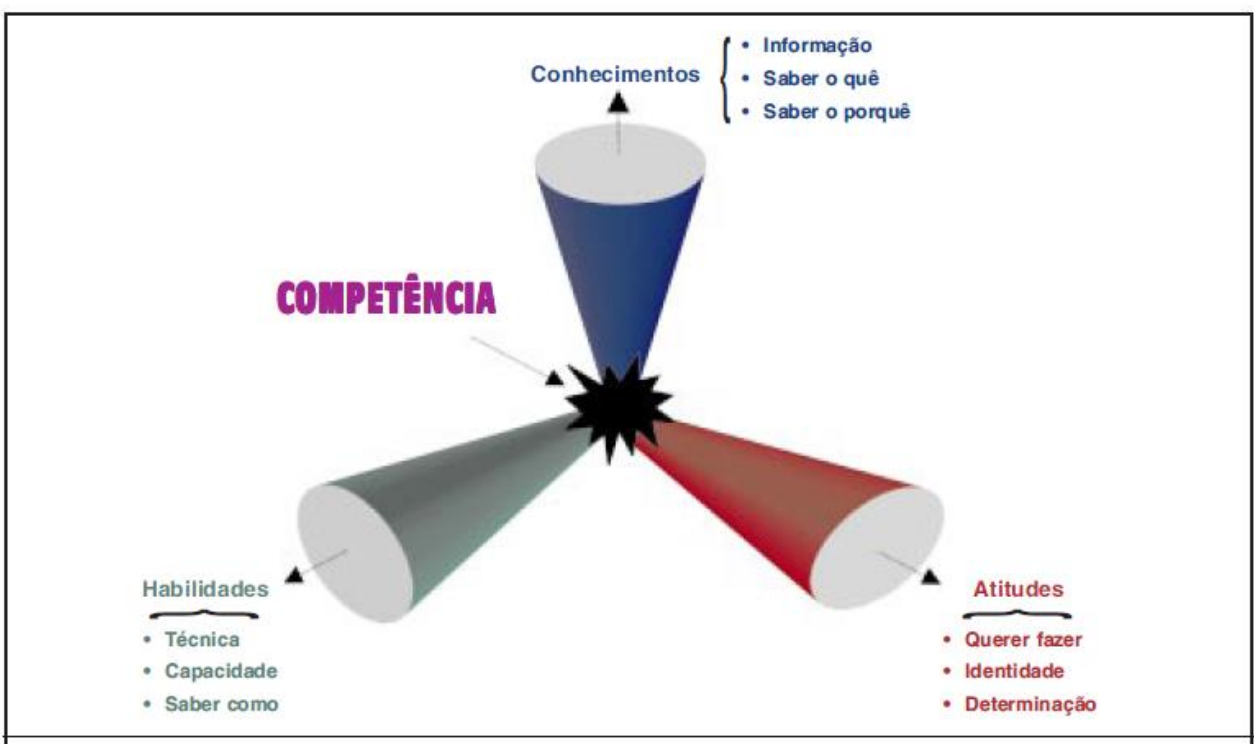

Fonte: Brandão e Guimarães (2001, p. 10).

Não há como dizer qual dessas dimensões é a mais importante ou a que teria prioridade de desenvolvimento, uma vez que uma completa a outra. No entanto, é possível constatar a necessidade do indivíduo em percorrer esses três caminhos, de modo que possa desenvolver e colocar em prática suas competências. Segundo Dutra (2003), para haver competência, não basta que o colaborador possua conhecimentos, habilidades e atitudes, é preciso que ele as utilize ao desenvolver suas atividades, apenas assim agregará valor à organização:

Um aspecto fundamental para o desenvolvimento de competências refere-se à apropriação do conhecimento (saber) em ações no trabalho (saber agir) para que seja possível desenvolver as competências, viabilizando práticas condizentes com o conhecimento adquirido. [...] O desenvolvimento de competências agrega valor ás atividades e à organização. Isto é, o conhecimento, se não for incorporado às atitudes e manifestar-se por meio de ações ou práticas no trabalho, não trará benefícios à organização nem estimulará o desenvolvimento das pessoas. (BITENCOURT, 2001, p. 35).

Portanto, não basta às organizações se preocuparem apenas com o fato de seus colaboradores possuírem requisitos preestabelecidos (habilidades, conhecimentos e atitudes), necessários para as funções que desempenham, pois um colaborador só agregará valor à 
organização se ele tiver a capacidade de mobilizar tais requisitos ao desenvolver suas tarefas, desta forma, alcançando a competência.

Alguns autores defendem que as competências individuais possuem uma subclassificação, seria uma série de competências inerentes a indivíduos e não a grupos. Essas seriam as denominadas competências gerenciais, que seriam responsáveis por "colocar as propostas e projetos em ação" e oportunizar o desenvolvimento das competências nas demais dimensõ es, seja ela organizacional ou funcional (RUAS, 2003, p. 8). Segundo Dutra (2003), na competência gerencial estão contidas competências essenciais, tais como: orientação estratégica, liderança, gestão de processos de mudança e gestão de recursos.

Com base nos autores acima citados, é possível pressupor que as competências gerenciais formam um elo entre as competências individuais e coletivas, uma vez que seriam elas encarregadas de mobilizar as competências dos indivíduos de um grupo, de modo a colaborarem entre si, e ainda traçando o alinhamento com a estratégia organizacional, dando origem às competências funcionais, organizacionais (essenciais), contribuindo, desta maneira, para o alcance dos objetivos da organização.

No que diz respeito às competências coletivas, também conhecidas como competências organizacionais ou essenciais, são resultantes da sinergia entre as competências individuais, daqueles que compõem um grupo, time, equipe, etc. Segundo Zarifian (2001), é importante destacar que o resultado da fusão de competências individuais pode não ser apenas o fortalecimento de uma determinada competência que a organização já possui, mas, sim, o surgimento de uma ou mais competências inéditas, dando origem a competências organizacionais ou o tão almejado diferencial competitivo. "Em uma equipe ou grupo de trabalho surge uma competência coletiva que é mais do que a soma das competências individuais. Isso se explica plenamente pelos efeitos de sinergia entre estas competências e pelas interações sociais a tivadas no seio do grupo". Ainda segundo esse autor, a competência coletiva só acontece quando as pessoas constroem referências semelhantes ou idênticas, compartilham objetivos e necessidades, buscando, assim, a cooperação e o alcance das metas pautadas pela organização (ZARIFIAN, 2001, p. 117).

O diferencial competitivo concede à organização uma vantagem perante as demais, mas o desafio está na capacidade dos gestores de mobilizar os recursos responsáveis pelo alcance de tais conquistas, no sentido de desenvolver e estimular as pessoas a entregarem todo o seu potencial em prol da organização. Dessa forma, desenvolvendo suas competências individuais e, consequentemente, contribuindo para desenvolvimento das competências organizacionais. Segundo Prahalad (1999), o desenvolvimento de competências se dá em três níveis: individual, grupos familiares e empresa, não devendo focar somente no desenvolvimento das capacidades analíticas. É preciso englobar os processos e valores, dando a devida importância à capacitação de processos e comportamentos, sendo crucial haver processos que otimizem a capacidade das equipes de desenvolver habilidades especiais que se transformarão em expertise da equipe e em capacidade de toda a organização.

\subsection{A gestão de pessoas na contemporaneidade}

A estrutura das organizações vem passando por inúmeras mudanças nas últimas décadas, e as empresas se veem forçadas a buscar adequação às demandas que surgem constantemente. A globalização e o fácil acesso aos recursos tecnológicos impõem um aumento voraz da concorrência, fazendo com que a busca pela "estabilidade no mercado" (no atual contexto inalcançável) transforme-se na "busca de inovação e oportunidade na instabilidade contínua" (TRASATTI; COSTA, 2010, p. 15). Em meio a esse cenário, gestão se tonou a palavra de ordem. Quando associada à administração, esse conceito assume, para Fischer (2001, p. 19), como: 
Uma ação para a qual há um menor grau de previsibilidade sobre o resultado do processo a ser "gerido". Um navio é dirigido, uma empresa é administrada, mas uma relação humana pode no máximo ser gerida - isso quando se admite que os dois agentes possuem consciência e vontade próprias.

A gestão de pessoas assume, no contexto específico, um novo significado e uma nova importância dentro das organizações. Para Mañas (2007), a prática abandona de vez o posicionamento de apenas buscar atender à satisfação das necessidades básicas das pessoas que prestam serviços internamente. Essa posição remete ao ambiente típico da Revolução Industrial. Passa a assessorar os gestores em atividades complexas, torna-se peça fundamental para a macroestratégia, colaborando com todos os níveis da empresa e sendo responsável por garantir o posicionamento da organização frente ao mercado externo. Para alguns autores, o novo conceito sugere inclusive uma mudança de nomenclatura para área. Fischer (2001, p. 20) tem como sugestão "modelo de gestão de pessoas" e a conceitua como "o conjunto de políticas, práticas padrões atitudinais, ações e instrumento empregados por uma empresa para interferir no comportamento humano e direcioná-lo no ambiente de trabalho".

Assim, a gestão de pessoas na necessidade de traduzir da melhor e mais detalhada forma possível seus desejos de resultados a seus colaboradores e, ao mesmo tempo, demonstrar que o alcance de tais resultados trará oportunidades financeiras, sociais e psicológicas, de forma a motiválos. Encontrou-se a solução para essa busca na gestão por competências. A ferramenta demonstra capacidade de comunicar ao colaborador o que a empresa espera dele; como ele está indo; quais os pontos a melhorar, como e para quê (TRASATTI; COSTA, 2010). Dessa forma, apresenta-se a gestão por competências, uma ferramenta que promete soluções para muitos dos questionamentos originados nessa nova perspectiva da gestão de pessoas, que passa a assumir um novo e decisivo papel, o de disseminar e auxiliar na concretização da estratégia organizacional.

\subsection{Compreendendo o modelo de gestão por competências}

O surgimento da gestão por competências se dá na busca dos gestores por respostas a questões inerentes ao contexto empresarial, que, devido às constantes mudanças, exige cada vez mais preparo das organizações que buscam destaque, ou até mesmo sobrevivência, neste cenário tão competitivo. São inúmeros os desafios que se apresentam: a necessidade de superar a concorrência em um mercado globalizado, a busca contínua pela inovação, qualidade e agilidade. Assim, a gestão por competências pode ser definida como uma metodologia capaz de orientar as organizações para o mercado e para o cliente, visando ao desenvolvimento profissional e organizacional. (CARBONE; RUFATTO JUNIOR, 2006).

Trata-se de uma gestão focada em suprir as competências necessárias para que a organização desenvolva seu diferencial competitivo sustentável. Considera-se, ainda, que a posse de recursos raros, valiosos e de difícil imitação confere à organização vantagem competitiva. A representação desses recursos ocorre através dos conhecimentos e competências das pessoas que fazem parte da organização (CARBONE; RUFATTO JUNIOR, 2006).

Com a gestão por competências, a percepção de ganho abrange não somente a organização, mas também as pessoas. As empresas percebem o ganho financeiro através do alcance da competência organizacional e, com isto, o sucesso de suas operações no mercado, enquanto os colaboradores logram o ganho social. Fleury e Fleury (2001, p. 194), em seu trabalho de conceituação das competências, lança luz sobre a perspectiva de ganho com a implementação dessa ferramenta:

Se por um lado, agrega valor econômico à organização, por outro, e não menos relevante, deve agregar valor social ao indivíduo, ou seja, as pessoas, ao desenvolverem competências essenciais para o sucesso da empresa, estão também investindo em si mesmas não só 
como cidadãos organizacionais, mas como cidadãos do próprio país e do mundo.

O ganho econômico agregado à organização é explícito e de fácil mensuração, pois é demonstrado pela aquisição de competências organizacionais que refletem no crescimento ou desenvolvimento da mesma. No entanto, a menção de ganho social para as pessoas, devido à amplitude da palavra social, pode dar um sentido muito subjetivo a tal ganho. Devido a isso, torna-se prudente definir um significado a esse termo. Segundo Sarsur (2007, p. 99-100), o ganho social pode ser conceituado como:

Um conjunto de aspectos que favorecem o desenvolvimento do trabalhador como ser humano, em sua dimensão mais ampliada: pessoal, profissional, cidadã (política e socialmente determinada). Nesse sentido, não é somente a perspectiva do desenvolvimento do indivíduo que conta, mas a sua inserção na sociedade e os impactos que, por meio dele, o grupo social pode auferir.

Não obstante, algumas críticas aos resultados do modelo de gestão por competências também são levantadas academicamente. Para Dutra (2003), ao citar cases de insucesso, ou aqueles que obtiveram resultados pobres, afirma que não se deve culpar a ferramenta devido a tais resultados, e sim as próprias organizações que utilizaram os conceitos de competência sem a utilização dos demais conceitos. No entanto, muitas restringiram seu uso para processos de recrutamento, seleção e desenvolvimento. Ainda, o autor destaca que:

O mau uso do conceito criou uma série de efeitos perversos. O mais sério desses efeitos é o aumento de pressão sobre as pessoas sem uma contrapartida da organização em termos de reconhecimento e da criação de condições concretas para desenvolvimento profissional. (DUTRA, 2003, p. 4).

Para o sucesso da implantação da gestão por competências, torna-se necessário uma profunda revisão quanto ao conceito de competência, de forma a compreendê-lo, em toda a sua complexidade, e associá-lo a outros conceitos, permitindo, assim, um aprofundamento e melhor compreensão da gestão de pessoas nas empresas (DUTRA, 2003, p. 4). Mesmo com o aprofundamento acerca do termo competência, de acordo com Dutra, devido ao fator percepção humana, sempre haverá riscos de interpretações distorcidas. Contudo, é justamente na dimensão humana que se estabelece o principal ponto de ligação entre a temática voltada ao modelo de gestão por competências e o cooperativismo.

A essência da identidade cooperativista está nas pessoas, compreendendo-as como propulsoras de ações que visem apresentar soluções do tipo down-up, ou seja, que levam em consideração aspectos que normalmente são negligenciados nas perspectivas de empresas tipicamente capitalistas, entre estes a historicidade e os valores simbólicos que cada um de nós traz consigo.

É nesse sentido que compreende-se que prestar um serviço de qualidade requer uma postura que denote a vivência do espírito do cooperativismo em todas as rotinas relacionadas ao atendimento, gerando um círculo virtuoso de atitudes que tragam satisfação e maior qualidade no serviço prestado aos associados.

\section{Metodologia}

Buscando responder ao questionamento apresentado por este trabalho (que se insere na compreensão das competências que os funcionários da cooperativa "Gama" devem possuir para 
prestar um atendimento de qualidade?), procedeu-se uma pesquisa do tipo estudo aplicado. Foi uma pesquisa com abordagem qualitativa e com delineamento descritivo do tipo levantamento:

Em levantamentos o objetivo é obter informação sobre uma população. São apropriados para pesquisa-diagnósticos. Pesquisas de caráter descritivo não procuram explicar algumas coisas ou mostrar relações causais, como pesquisas de caráter experimental. Censos, levantamentos de opinião pública ou pesquisas de mercado procuram fatos descritivos; buscam informação necessária para a ação ou predicação. Pesquisas descritivas não respondem bem ao por que, embora possam associar certos resultados a grupos de respondentes. (ROESCH, 2009, p. 137).

Foi utilizado esse tipo de estudo por melhor se adequar à proposta deste trabalho. Além disso, o quadro funcional é relativamente pequeno, o que possibilitou abrangê-lo de forma integral, mais uma característica que remete a esse tipo de estudo. Para Roesch (2009, p. 137):

Levantamentos de atitudes dentro das organizações é outro exemplo de pesquisa descritiva muito utilizada. Enquanto na pesquisa de mercado se trabalha com amostragem, nos levantamentos de atitudes geralmente se trabalha com toda a população.

A população alvo foi à totalidade do quadro funcional de cooperativa de economia e crédito mútuo, composto de quatro colaboradores, que foi denominada "Gama", sediada na cidade de Porto Alegre, Estado do Rio Grande do Sul.

A "Gama" é uma cooperativa de economia e crédito mútuo, que atende os colaboradores ativos e inativos de um banco sediado em Porto Alegre, capital do Rio Grande do Sul. Hoje, a cooperativa "Gama" conta com cerca de cinco mil associados. Fundada em meados da década de 1940, inicialmente, limitava-se a atender os funcionários ativos da agência matriz do banco. Após cerca de 20 anos de sua fundação, obteve junto aos órgãos de fiscalização competentes, autorização para expandir a abrangência de seu atendimento aos funcionários ativos do banco, das agências localizadas em Porto Alegre e região metropolitana. Somente mais tarde, foi-lhe concedida a possibilidade de atender todos os funcionários do banco, em nível nacional, independentemente de suas situações.

A cooperativa conta com um quadro de 15 colaboradores, distribuídos em 11 funções. Toda a estrutura funcional está submetida a uma diretoria, que compreende as coordenações executiva e fiscal, cuja ocupação ocorre conforme eleição direta, em Assembleia Geral Extraordinária.

A cooperativa "Gama" demonstra estar atenta às tendências das melhores práticas de gestão difundidas no mercado, sendo notória a preocupação e esforço na busca pela profissionalização, evidenciadas no plano estratégico descrito abaixo'.

- Negócio: intermediação, Serviços e Educação Financeira.

- Visão: ser reconhecida como cooperativa de crédito referência em qualidade de gestão e governança no atendimento de demandas relacionadas às finanças pessoais de seus cooperados.

- Missão: propiciar o desenvolvimento do hábito de poupança, oportunizando a mutualidade financeira e a realização dos projetos pessoais de seus cooperados.

Atenta a uma gestão eficiente dos seus recursos humanos, buscou auxílio junto a uma empresa de assessoria especializada para desenvolver e implantar uma ferramenta baseada em perfis de competências. Os objetivos estabelecidos foram: criar funções distintas; estabelecer estoques de competências necessárias para um bom desempenho nestas funções; construir, a partir das funções, perfis; distribuir o quadro funcional nestas funções de acordo com o potencial de cada um e, por fim;

\footnotetext{
${ }^{1}$ Conforme o site da instituição.
} 
obter uma tecnologia que trouxesse a satisfação do colaborador por meio de um plano de carreira e, ao mesmo tempo, garantir o alcance dos objetivos estratégicos da organização. Durante o processo de implantação da ferramenta, os colaboradores tiveram espaço para expor suas necessidades e expectativas, que, posteriormente, a empresa consultora, juntamente com os gestores, sintetizou e utilizou como apoio ao delineamento do modelo de gestão. Após a implantação, foram disponibilizados treinamentos à equipe e também individualizados aos colaboradores, visando à redução das lacunas existentes entre as competências estabelecidas como necessárias pela organização, e as que os colaboradores possuíam no momento da realocação de função.

Para realizar a coleta de dados, optou-se pela aplicação de um questionário para medir a percepção dos colaboradores. Roesch (2009, p. 142) define questionário como sendo um "instrumento de coleta de dados que busca mensurar alguma coisa. Para tanto, requer esforço intelectual anterior de planejamento, com base na conceituação do problema da pesquisa e do plano da pesquisa, e algumas entrevistas exploratórias preliminares". Foi realizada previamente uma entrevista com a gerência da cooperativa de crédito "Gama", na qual se investigou o grau de abrangência da ferramenta de gestão por competências, na organização, como se deu a implantação, mensuração dos resultados e perspectivas dos gestores. Nesse momento, foi relatado pela cooperativa que o modelo implantado se tratava de uma ferramenta de gestão baseada em perfis de competências, e que, no processo de implantação, os colaboradores foram submetidos a um nivelamento de conhecimento quanto à conceituação do termo competência. Nessa direção, partiuse do pressuposto que os colaboradores estão qualificados e aptos a responder a pesquisa.

O questionário utilizado na pesquisa é resultado da adaptação do elaborado e utilizado no estudo realizado por Brandão (1999). O autor trabalhou na mensuração da percepção dos gestores, funcionários e clientes em relação às competências profissionais que funcionários de agências do Banco do Brasil, no Distrito Federal, deveriam possuir para prestar um atendimento de qualidade ao cliente. Há uma grande semelhança entre os objetivos da pesquisa citada acima e a proposta neste trabalho, por isso optou-se por adaptá-lo e utilizá-lo.

Para obter o grau de importância atribuído às 46 competências descritas no questionário, o autor utilizou uma escala de avaliação do tipo diferencial semântico (escala de Osgood), constituída de seis pontos (numerados de um a seis), utilizando em suas extremas expressões de sentidos opostos (nem um pouco importante e extremamente importante) para classificação das competências. Assim, quanto mais próxima do número um for a resposta, menor será a importância atribuída pelo entrevistado à competência, e quanto mais próxima do número seis, maior é a importância da competência ao perfil do colaborador. Na presente pesquisa, foi utilizado o mesmo método do autor acima citado, com mensuração de um a seis pontos.

Como se trata de organizações pertencentes ao setor financeiro e, apesar de possuírem características distintas, seus produtos e serviços são bastante parecidos e as competências para um atendimento de qualidade se assemelham. Por isso, não se fizeram necessárias muitas alterações no conteúdo do questionário. As adaptações consistiram na substituição de palavras ou termos que fossem mais apropriadas ao segmento de cooperativas de crédito ou a própria pesquisa.

Ao todo, o questionário possui 58 questões objetivas, distribuídas em quatro seções: a) conhecimentos, com 13 questões; b) habilidades, com 17 questões; c) atitudes, com 16 questões e d) dados do respondente, com questões que buscam delinear o perfil do respondente. Nas seções a, b e c, cada questão objetiva apresentava ao pesquisado uma competência para a qual ele deveria atribuir um grau de importância na escala, de acordo com sua percepção. Antecedendo cada seção, havia uma breve explicação ilustrada de como assinalar as respostas. 


\section{Resultados e análise}

O quadro abaixo apresenta os resultados obtidos em termos de média, desvio padrão e coeficiente de variação, em cada item do instrumento utilizado.

Quadro 1 - Classificação das competências segundo a percepção dos colaboradores da cooperativa "Gama"

\begin{tabular}{|c|c|c|c|}
\hline \multicolumn{2}{|c|}{ Mais Importantes } & \multicolumn{1}{c|}{} & C. \\
\hline Descrição das variáveis & $\mathrm{X}$ & $\mathrm{V}$. & $\mathrm{0} \%$ \\
\hline $\begin{array}{c}\text { V35. Demonstrar receptividade ao associado } \\
\text { (manifestar satisfação, disponibilidade e interesse } \\
\text { em atender o associado). }\end{array}$ & 6,00 & 0,00 & $7 \%$ \\
\hline $\begin{array}{c}\text { V2. Conhecer os produtos e serviços da } \\
\text { "Gama". }\end{array}$ & 5,80 & 0,41 & $8 \%$ \\
\hline V37. Demonstrar cortesia e educação. & 5,73 & 0,46 & $8 \%$ \\
\hline $\begin{array}{c}\text { V43. Ser ético na relação com os associados } \\
\text { (reconhecer e valorizar a conduta correta). }\end{array}$ & 5,73 & 0,46 & \\
\hline
\end{tabular}

(continuação)

\begin{tabular}{|c|c|c|c|}
\hline \multicolumn{4}{|l|}{ Muita importância } \\
\hline Descrição das variáveis & $\mathrm{X}$ & $\sigma$ & C.V. \\
\hline $\begin{array}{l}\text { V15. Ser capaz de identificar as características e } \\
\text { expectativas do associado em relação à "Gama". }\end{array}$ & 5,67 & 0,49 & $9 \%$ \\
\hline $\begin{array}{l}\text { Vig. Ser capaz de comunicar-se com clareza e } \\
\text { objetividade. }\end{array}$ & 5,67 & 0,49 & $9 \%$ \\
\hline $\begin{array}{l}\text { V36. Demonstrar empatia ao associado (saber colocar-se } \\
\text { no lugar do associado). }\end{array}$ & 5,60 & 0,51 & $9 \%$ \\
\hline $\begin{array}{l}\text { V42. Demonstrar paciência (ser tolerante e estar disposto } \\
\text { a ouvir o associado). }\end{array}$ & 5,60 & 0,51 & $9 \%$ \\
\hline $\begin{array}{l}\text { V33. Reconhecer } \\
\text { a importância } \\
\text { atendimento de qualidade. }\end{array}$ & 5,60 & 0,51 & $9 \%$ \\
\hline $\begin{array}{l}\text { V46. Manifestar desejo de aprender continuamente e } \\
\text { aprimorar-se profissionalmente. }\end{array}$ & 5,60 & 0,63 & $11 \%$ \\
\hline V48. Respeitar a privacidade do associado. & 5,60 & 0,63 & $11 \%$ \\
\hline $\begin{array}{l}\text { V1. Conhecer a "Gama" (sua estrutura, funcionamento, } \\
\text { estratégia, missão, políticas e objetivos). }\end{array}$ & 5,53 & 0,52 & $9 \%$ \\
\hline $\begin{array}{l}\text { V16. Ser capaz de utilizar uma linguagem acessível ao } \\
\text { associado (saber falar a "língua" do associado). }\end{array}$ & 5,53 & 0,52 & $9 \%$ \\
\hline $\begin{array}{l}\text { V21. Ser capaz de produzir soluções rapidamente } \\
\text { (demonstrar agilidade). }\end{array}$ & 5,53 & 0,52 & $9 \%$ \\
\hline $\begin{array}{l}\text { V38. Reconhecer a importância do associado para a } \\
\text { "Gama". }\end{array}$ & 5,53 & 0,52 & $9 \%$ \\
\hline $\begin{array}{l}\text { V3. Conhecer o ambiente em que a "Gama" atua (mercado } \\
\text { local, negócios e concorrência local). }\end{array}$ & 5,53 & 0,64 & $12 \%$ \\
\hline $\begin{array}{l}\text { V17. Ser capaz de manter boas relações interpessoais com } \\
\text { associados e colegas. }\end{array}$ & 5,53 & 0,64 & $12 \%$ \\
\hline
\end{tabular}

${ }^{2}$ Onde X é a média; $\sigma$ é o desvio padrão e C.V. é o coeficiente de variação. 
11 | Gestão por competências: a percepção dos colaboradores de uma cooperativa de crédito

\begin{tabular}{|c|c|c|c|}
\hline $\begin{array}{l}\text { V23. Ser capaz de argumentar de maneira convincente (saber } \\
\text { sustentar seus argumentos sobre produtos e serviços da cooperativa, } \\
\text { mercados, negócios etc) }\end{array}$ & 5,53 & 0,64 & $12 \%$ \\
\hline $\begin{array}{l}\text { V27. Ser capaz de conquistar a simpatia e o apreço do } \\
\text { associado. }\end{array}$ & 5,53 & 0,64 & $12 \%$ \\
\hline \multicolumn{4}{|c|}{ Média importância } \\
\hline Descrição das variáveis & $\mathrm{X}$ & $\sigma$ & C.V. \\
\hline V24. Ser capaz de identificar oportunidades negociais. & 5,47 & 0,52 & $9 \%$ \\
\hline $\begin{array}{l}\text { V45. Assumir a responsabilidade frente a situações de } \\
\text { trabalho para responder a contento às demandas do associado e da } \\
\text { cooperativa. }\end{array}$ & 5,47 & 0,74 & $14 \%$ \\
\hline $\begin{array}{l}\text { V41. Dispensar igualdade de tratamento aos associados } \\
\text { (reconhecer igualmente o direito de cada associado, sem } \\
\text { discriminação). }\end{array}$ & 5,40 & 0,51 & $9 \%$ \\
\hline $\begin{array}{l}\text { V } 5 \text {. Conhecer as rotinas e processos relativos ao seu } \\
\text { trabalho. }\end{array}$ & 5,40 & 0,74 & $14 \%$ \\
\hline
\end{tabular}

(conclusão)

\begin{tabular}{|c|c|c|c|}
\hline $\begin{array}{l}\text { V28. Ser observador e perceber os fatos que o cercam e suas } \\
\text { consequências (ser perspicaz) }\end{array}$ & 5,40 & 0,74 & $4 \%$ \\
\hline V34. Demonstrar pró-atividade (tomar a iniciativa). & 5,40 & 0,83 & $5 \%$ \\
\hline $\begin{array}{l}\text { V40. Demonstrar disposição para reposicionar-se em razão de } \\
\text { mudanças nos desejos do associado, nos objetivos da cooperativa, no } \\
\text { ambiente, etc (ser flexível). }\end{array}$ & 5,33 & 0,72 & $4 \%$ \\
\hline $\begin{array}{l}\text { V2o. Ser capaz de encontrar as informações de que necessita } \\
\text { para o trabalho. }\end{array}$ & 5,33 & 0,82 & $5 \%$ \\
\hline V47. Demonstrar modéstia (humildade). & 5,27 & 0,88 & $7 \%$ \\
\hline $\begin{array}{l}\text { V25. Ser capaz de identificar o risco e a rentabilidade dos } \\
\text { negócios, avaliando os principais aspectos envolvidos. }\end{array}$ & 5,13 & 0,74 & $4 \%$ \\
\hline $\begin{array}{l}\text { V44. Demonstrar responsabilidade social (preocupar-se com } \\
\text { as consequências de seus atos para a sociedade como um todo). }\end{array}$ & 5,13 & 0,74 & $4 \%$ \\
\hline V26. Ser capaz de produzir soluções criativas e inovadoras. & 5,07 & 0,70 & $4 \%$ \\
\hline V8. Conhecer princípios de qualidade em serviços. & 5,07 & 0,80 & $6 \%$ \\
\hline $\begin{array}{l}\text { V3o. Ser capaz de resolver problemas não convencionais, } \\
\text { inéditos ou surpreendentes. }\end{array}$ & 5,00 & 0,93 & $9 \%$ \\
\hline \multicolumn{4}{|l|}{ Moderada ou pouca importância } \\
\hline Descrição das variáveis & $\mathrm{X}$ & $\sigma$ & .V. \\
\hline $\begin{array}{l}\text { V22. Ser capaz de integrar-se a diferentes contextos sociais } \\
\text { (saber relacionar-se com diferentes pessoas, culturas, situações etc). }\end{array}$ & 4,93 & 0,70 & $4 \%$ \\
\hline $\begin{array}{l}\text { V6. Conhecer princípios de marketing (negociação, vendas, } \\
\text { segmentação etc.). }\end{array}$ & 4,93 & 0,80 & $6 \%$ \\
\hline $\begin{array}{l}\text { V39. Demonstrar sensibilidade em relação aos problemas e } \\
\text { dificuldades do associado. }\end{array}$ & 4,93 & 0,80 & $6 \%$ \\
\hline $\begin{array}{l}\text { V29. Ser capaz de trabalhar sob pressão, administrando o } \\
\text { stress. }\end{array}$ & 4,93 & 0,96 & $9 \%$ \\
\hline $\begin{array}{l}\text { V18. Ser capaz de operar computadores, periféricos e outros } \\
\text { recursos tecnológicos. }\end{array}$ & 4,67 & 0,62 & $3 \%$ \\
\hline $\begin{array}{l}\text { V31. Ser capaz de antever o futuro em razão de tendências (ter } \\
\text { visão de futuro). }\end{array}$ & 4,67 & 0,82 & $7 \%$ \\
\hline Vı. Conhecer princípios de economia. & 4,40 & 0,63 & $4 \%$ \\
\hline
\end{tabular}

Fonte: Elaborado pelos autores. 
Considera-se grande dispersão quando o coeficiente de variação apresenta resultado acima de 20\%. Das 46 competências apresentadas na pesquisa (portanto, presentes no questionário), seis tiveram resultados superiores a $20 \%$, sendo elas: $\mathrm{V}_{4}$. Conhecer princípios de contabilidade e finanças, $V_{7}$. Conhecer como funcionam os mercados financeiro e de capitais, V9. Conhecer idiomas estrangeiros, principalmente o inglês, V.11. Conhecer diferentes sistemas de informática (softwares, Internet etc), V12. Conhecer princípios de relações humanas e V13. Conhecer a conjuntura social, política e econômica do País. Um aspecto a destacar é o fato das seis questões excluídas pertencerem à seção que abordava as competências relativas a conhecimentos. A alta dispersão pode estar indicando que elas não estão diretamente relacionadas com a realidade atual da cooperativa "Gama".

As outras 40 competências apresentaram coeficientes de variação inferiores a $20 \%$, portanto, classificadas como pequena e média dispersão. Assim sendo, foram consideradas na análise. A relação das competências essenciais para um atendimento de qualidade, segundo a percepção dos colaboradores da cooperativa "Gama", em relação ao questionário aplicado, está descrita na Tabela 2. Os critérios utilizados para determinar a classificação das competências baseiam-se nos utilizados por Brandão (1999, 88-89), foram agrupadas em blocos, de acordo com o grau de importância atribuído a elas. Para isso, foi considerada a média e o desvio padrão de cada variável. Ao todo, são cinco blocos: Menos importantes, com médias de até 4; Moderada ou pouca importância, para médias acima de quatro e inferiores a cinco; Média importância, para médias entre 5 e 5,50; Muita importância, abrangendo médias entre 5,51 e 5,70; e Mais importantes, para médias superiores a 5,70. As competências: Demonstrar receptividade ao associado (manifestar satisfação, disponibilidade e interesse em atender o associado), Conhecer os produtos e serviços da Gama, Demonstrar cortesia e educação e Ser ético na relação com os associados (reconhecer e valorizar a conduta correta) obtiveram os maiores escores, estando classificadas no bloco Muito importantes. Ao todo, 19 competências obtiveram médias superiores a 5,50. Isso pode ser interpretado como um indício de que essas competências seriam essenciais para um atendimento de qualidade segundo os colaboradores, levando-se em conta que a média máxima é seis.

Analisando-se os resultados sob a ótica das dimensões conhecimentos, habilidades e atitudes, nas quais as competências foram distribuídas no questionário, constata-se que, entre as 11 competências com maiores médias, oito delas fazem referência às atitudes. Ainda, as variáveis $V_{33}$ a $\mathrm{V} 48$, compreendidas na dimensão atitudes, obtiveram $\mid \mathrm{X}=5,50$, resultado superior ao registrado entre as variáveis $V_{1}$ a $V_{13}$, que descrevem conhecimentos $X=4,73$, e também das contidas na dimensão habilidades $V_{15}$ a $V_{31}$, com $X=5,27$. Demonstra-se, assim, que as atitudes são mais valorizadas na visão dos colaboradores.

Diferentemente dos resultados descritos por Brandão (1999, p.89-93), nenhuma das variáveis classificadas obteve média inferior a 4,40. Para tanto, não se classificou nenhuma competência como "menos importante". Isso pode ter sido ocasionado pela diferença do tamanho das amostras. Todavia, 21 variáveis foram classificadas como moderada ou pouca importância e média importância, devido as suas médias terem alcançado entre 4,40 e 5,47.

As variáveis V29, V30, V31, V47, V6, V39 e V8 apresentaram coeficiente de variação superior a $15 \%$. No entanto, todas elas pertencem aos blocos média, moderada ou pouco importante.

Os resultados obtidos nessa etapa sugerem que as competências apresentadas no questionário são relevantes para a prestação de um atendimento com qualidade, exceto pelas variáveis descritas no início deste capítulo, que, por apresentarem alta dispersão, foram excluídas da análise. Destaca-se que as competências relacionadas a atitudes foram as mais valorizadas, na visão dos colaboradores. A seguir, serão expostas as competências que foram eleitas como essenciais para prestar um atendimento de qualidade segundo este estudo. 


\subsection{Formulando um perfil de competências}

Com base nos resultados obtidos por meio do questionário aplicado junto aos colaboradores da cooperativa "Gama", formulou-se um perfil de competências necessárias para que colaboradores da cooperativa possam prestar um atendimento de qualidade demostrado no quadro abaixo:

Quadro 2: Perfil de competências baseado nos resultados quantitativos da pesquisa

\begin{tabular}{|l|}
\hline \multicolumn{1}{|c|}{ Conhecimentos } \\
\hline V1. Conhecer a "Gama" (sua estrutura, funcionamento, estratégia, missão, políticas e objetivos); \\
V2. Conhecer os produtos e serviços da "Gama"; \\
V3. Conhecer o ambiente em que a "Gama" atua (mercado local, negócios e concorrência); \\
\hline Habilidades \\
\hline V15. Ser capaz de identificar as características e expectativas do associado em relação à "Gama"; \\
V16. Ser capaz de utilizar uma linguagem acessível ao associado (saber falar a "língua" do associado); \\
V17. Ser capaz de manter boas relações interpessoais com associados e colegas; \\
V19. Ser capaz de comunicar-se com clareza e objetividade; \\
V21. Ser capaz de produzir soluções rapidamente (demonstrar agilidade). \\
V23. Ser capaz de argumentar de maneira convincente (saber sustentar seus argumentos sobre produtos e \\
V27. Ser capaz de conquistar a simpatia e o apreço do associado; \\
Atitudes \\
\hline V33. Reconhecer a importância de prestar um atendimento de qualidade; \\
V35. Demonstrar receptividade ao associado (manifestar satisfação, disponibilidade e interesse em atender o \\
Vassociado); \\
V36. Demonstrar empatia ao associado (saber colocar-se no lugar do associado); \\
V37. Demonstrar cortesia e educação; \\
V38. Reconhecer a importância do associado para a "Gama”; \\
V42. Demonstrar paciência (ser tolerante e estar disposto a ouvir o associado); \\
V43. Ser ético na relação com os associados (reconhecer e valorizar a conduta correta); \\
V46. Manifestar desejo de aprender continuamente e aprimorar-se profissionalmente; \\
V48. Respeitar a privacidade do associado. \\
\hline
\end{tabular}

Fonte: Elaborado pelo autor.

Buscando obter um perfil de competências que represente a percepção dos respondentes, com alto grau de fidedignidade, foram utilizadas somente as competências classificadas como "mais importantes" e de "muita importância", devido às altas médias, baixos desvios padrões e coeficientes de variação alcançados nestas categorias. O resultado pode ser observado no Quadro 1, no qual observa-se a classificação e descrição das competências que constituem o perfil. Ao todo, são 19 competências, classificadas da seguinte forma: três conhecimentos, sete habilidades e nove atitudes.

\subsection{Análise do perfil de competências existente na cooperativa “Gama”}

A cooperativa "Gama" contou com o auxílio de assessoria especializada no desenvolvimento e implantação de um modelo de gestão baseado em perfis de competências, conforme descrito pela gerência da cooperativa.

É possível observar que, no perfil de competências detalhado no Quadro 9, a partir de agora, denominar-se-á "Perfil Gama". As habilidades e atitudes são descritas, em sua quase totalidade, por mono palavras, diferentemente da descrição apresentada no questionário aplicado, em que a descrição se faz de uma maneira mais delimitada, como é recomendado por Carbone et al (apud BRANDÃO; BAHRY, 2005). Segundo o autor, o mais indicado é descrever as competências através de comportamentos objetivos e que possibilitem a observação no ambiente de trabalho, pois, quando a descrição não é clara, as pessoas podem interpretar de maneira errônea. Para Brandão e Bahry (2005, p.183), a descrição das competências deve "representar um desempenho ou comportamento esperado, indicando o que o profissional deve ser capaz de fazer. Esse comportamento deve ser descrito utilizando-se um verbo e um objeto de ação". 
Quadro 3: "Perfil Gama”

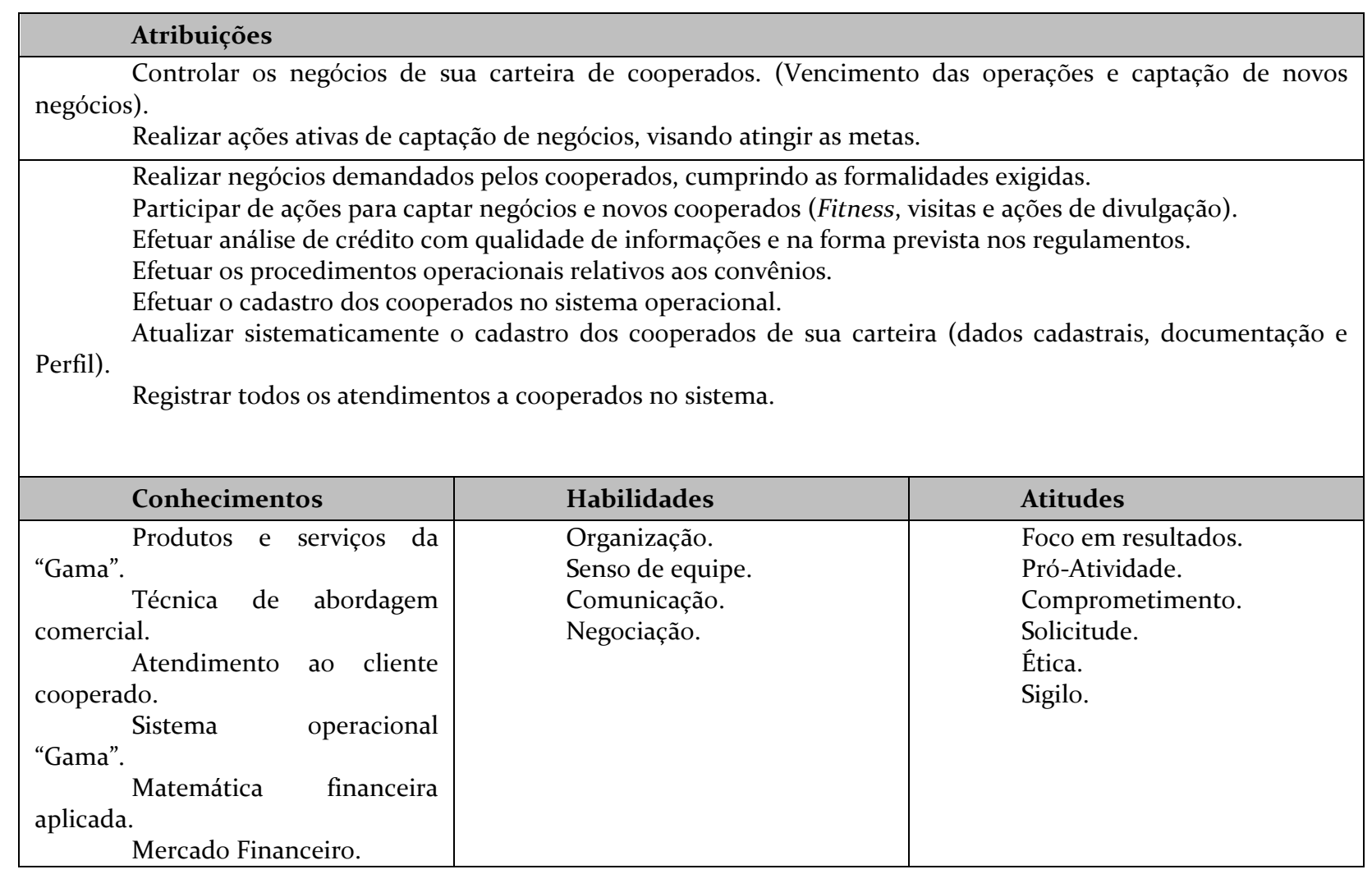

Fonte: Ferramenta de gestão desenvolvida pela Cooperativa "Gama".

\subsection{Semelhanças identificadas}

A seguir, no Quadro 10, estão demonstrados os resultados da análise comparativa, entre as competências eleitas pelos colaboradores neste estudo por meio do questionário e as respectivas equivalentes ou similares, que compõem o perfil de competências implantado na "Gama".

Quadro 4: Comparação das competências percebidas pelos colaboradores e o "Perfil Gama"

\begin{tabular}{|c|c|c|}
\hline & $\begin{array}{c}\text { Competências, } \\
\begin{array}{c}\text { colaboradores da “Gama” } \\
\text { colando a }\end{array}\end{array}$ & $\begin{array}{l}\text { Competências correspondentes } \\
\text { no "Perfil Gama" }\end{array}$ \\
\hline \multirow{3}{*}{ 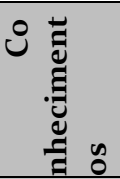 } & $\begin{array}{l}\text { Conhecer a "Gama" (sua estrutura, funcionamento, } \\
\text { estratégia, missão, políticas e objetivos). }\end{array}$ & Sistema operacional “Gama”. \\
\hline & Conhecer os produtos e serviços da "Gama". & Produtos e serviços da "Gama”. \\
\hline & $\begin{array}{l}\text { Conhecer o ambiente em que a "Gama” atua (mercado } \\
\text { local, negócios e concorrência local). }\end{array}$ & Mercado Financeiro. \\
\hline \multirow{4}{*}{ 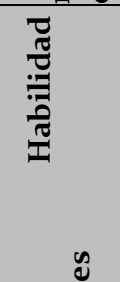 } & $\begin{array}{l}\text { Ser capaz de utilizar uma linguagem acessível ao } \\
\text { associado (saber falar a "língua" do associado). }\end{array}$ & \multirow[t]{2}{*}{ Comunicação. } \\
\hline & Ser capaz de comunicar-se com clareza e objetividade. & \\
\hline & $\begin{array}{l}\text { Ser capaz de manter boas relações interpessoais com } \\
\text { associados e colegas. }\end{array}$ & Senso de equipe. \\
\hline & $\begin{array}{l}\text { Ser capaz de argumentar de maneira convincente (saber } \\
\text { sustentar seus argumentos sobre produtos e serviços da } \\
\text { cooperativa, mercados, negócios etc.) }\end{array}$ & Negociação. \\
\hline \multirow{6}{*}{$\sum^{\frac{d}{2}}$} & $\begin{array}{c}\text { Demonstrar receptividade ao associado (manifestar } \\
\text { satisfação, disponibilidade e interesse em atender o associado). }\end{array}$ & \multirow{3}{*}{ Solicitude. } \\
\hline & Demonstrar cortesia e educação. & \\
\hline & $\begin{array}{l}\text { Demonstrar paciência (ser tolerante e estar disposto a } \\
\text { ouvir o associado). }\end{array}$ & \\
\hline & $\begin{array}{l}\text { Ser ético na relação com os associados (reconhecer e } \\
\text { valorizar a conduta correta). }\end{array}$ & Ética. \\
\hline & $\begin{array}{l}\text { Manifestar desejo de aprender continuamente e } \\
\text { aprimorar-se profissionalmente. }\end{array}$ & Pró-Atividade. \\
\hline & Respeitar a privacidade do associado & Sigilo. \\
\hline
\end{tabular}

Fonte: Elaborado pelo autor. 
Foi possível verificar que o fato da "Gama" descrever competências, na maioria das vezes apenas com uma palavra, tornou o significado das mesmas muito abrangentes. Como a análise baseou-se na equivalência de significado, algumas competências foram consideradas semelhantes, apesar de possuirem semânticas bastante diferentes.

Das 19 competências percebidas pelos colaboradores, foram encontradas 13 relações com as estabelecidas pelo "Perfil Gama". De fato, algumas semelhanças já eram esperadas, porém não se deve esquecer que os colaboradores estão cientes das competências que lhes são cobradas e isso pode ter influenciado nas suas respostas à pesquisa. No entanto, isso não invalida ou prejudica os resultados, uma vez que também podem estar demonstrando que existe uma concordância, assim confirmando a importância de tais competências.

A partir da identificação dessas semelhanças, torna-se possível identificar as diferenças entre os dois grupos de competências - os descritos na ferramenta de gestão utilizada pela empresa e os percebidos pelos colaboradores.

\subsection{Diferenças identificadas}

Foram consideradas diferenças, aquelas competências que, na comparação, não foi identificada nenhuma semelhança no sentido. Estão listadas no Quadro 4, em seus respectivos grupos de origem.

Quadro 5: Discordância entre competências percebidas pelos colaboradores e o "Perfil Gama"

(continua)

\begin{tabular}{|c|c|c|}
\hline & "Gama" Competências, segundo os colaboradores da & $\begin{array}{l}\text { Competências } \\
\text { "Perfil Gama" }\end{array}$ \\
\hline \multirow{3}{*}{ 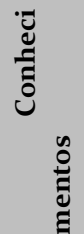 } & Sem equivalente. & $\begin{array}{l}\text { Atendimento } \\
\text { cliente cooperado }\end{array}$ \\
\hline & Sem equivalente. & $\begin{array}{l}\text { Matemática } \\
\text { financeira aplicada; }\end{array}$ \\
\hline & Sem equivalente. & $\begin{array}{c}\text { Técnica } \\
\text { abordagem comercial; }\end{array}$ \\
\hline
\end{tabular}

(conclusão)

\begin{tabular}{|c|c|c|}
\hline & Competências, segundo os colaboradores da "Gama" & Competências “Perfil Gama” \\
\hline \multirow{4}{*}{ 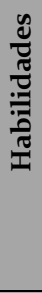 } & $\begin{array}{l}\text { Ser capaz de identificar as características e } \\
\text { expectativas do associado em relação à "Gama”. }\end{array}$ & Sem equivalente. \\
\hline & $\begin{array}{c}\text { Ser capaz de produzir soluções rapidamente } \\
\text { (demonstrar agilidade). }\end{array}$ & Sem equivalente. \\
\hline & $\begin{array}{l}\text { Ser capaz de conquistar a simpatia e o apreço do } \\
\text { associado. }\end{array}$ & Sem equivalente. \\
\hline & Sem equivalente. & Organização; \\
\hline \multirow{4}{*}{ 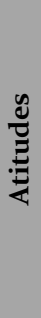 } & $\begin{array}{l}\text { Reconhecer a importância de prestar um atendimento } \\
\text { de qualidade. }\end{array}$ & Sem equivalente. \\
\hline & $\begin{array}{l}\text { "Geconhecer a importância do associado para a } \\
\text { "Gama". }\end{array}$ & Sem equivalente. \\
\hline & Sem equivalente. & Foco em resultados; \\
\hline & Sem equivalente. & Comprometimento; \\
\hline
\end{tabular}

Fonte: Elaborado pelos autores. 
Ao todo, seis competências de cada grupo não demonstraram relação entre si. No subgrupo conhecimentos, não se obteve nenhuma competência resultante da percepção dos colaboradores que não tenha sido relacionada com alguma das existentes no "Perfil Gama". Em contraponto, três pertencentes a esse segundo grupo não tiveram equivalentes. Em habilidades, três competências provenientes da percepção dos colaboradores não tiveram equivalentes e somente a competência Organização, do "Perfil Gama", não se equivaleu a nenhuma outra na comparação. Já em Atitudes, foram três eleitas pelos colaboradores e que não tiveram equivalentes. Destaca-se que o subgrupo das Atitudes obteve as maiores médias na pesquisa, o que indica alto grau de importância destas competências. Das atitudes do "Perfil Gama", duas não tiveram equivalentes na comparação com as apuradas, segundo os colaboradores.

Os resultados demonstrados possibilitaram a identificação de competências percebidas pelos colaboradores da "Gama" como importantes para que seja possível prestar um atendimento de qualidade e que não estão presentes no perfil de competências existente na organização.

\section{Considerações Finais}

A presente pesquisa teve como objetivo principal a identificação de competências profissionais relevantes à prestação de um atendimento de qualidade ao associado da cooperativa "Gama”. Segundo a percepção dos colaboradores da cooperativa, das 46 competências submetidas à avaliação, 40 foram consideradas relevantes. Outras seis competências não foram consideradas relevantes, por terem apresentado alto coeficiente de variação. Todas essas se referiam a conhecimentos. Para Fleury e Fleury (2001), o estoque de conhecimentos está atrelado às atividades desempenhadas pelos indivíduos, a qualificação necessária devido à posição ou cargos que ocupam. Isso pode indicar que essas competências não estão relacionadas diretamente às atuais atividades dos respondentes ou à realidade da "Gama".

Na comparação entre o "Perfil Gama" e o perfil de competências resultante da percepção dos colaboradores, foram identificadas semelhanças e diferenças que subsidiaram as sugestões de melhorias feitas neste estudo. Entende-se que as semelhanças indicam pontos de concordância, pois os resultados confirmam a importância das competências descritas no "Perfil Gama". No entanto, as diferenças demonstram dois resultados: competências identificadas conforme a percepção dos colaboradores, e que não possuem coincidentes no "Perfil Gama"; e as competências existentes no "Perfil Gama" sem coincidentes entre as percebidas pelos colaboradores. No primeiro resultado, evidenciam-se os conhecimentos, habilidades e atitudes que podem vir a contribuir para proporcionar um atendimento de qualidade aos sócios. No segundo, como este trabalho não tem como objetivo invalidar a ferramenta desenvolvida pela organização, não se procedeu uma análise criteriosa sobre essas competências.

A instituição analisada não possui postos de atendimento fora de sua sede, o que determina que seu quadro de colaboradores seja relativamente pequeno. Dessa forma, uma das limitações desta pesquisa refere-se ao tamanho da população, o que dificultou e restringiu o uso de ferramentas estatísticas para testar frequências e relações entre as variáveis. Também aumentou os riscos de distorção das informações coletadas. Em função do tamanho da população, não é possível generalizar os dados. Um próximo estudo poderia abranger um conglomerado de cooperativas, por intermédio de uma confederação ou central de cooperativas. Apesar das limitações encontradas, salienta-se que os resultados se mostram coerentes quando comparados à ferramenta utilizada pela cooperativa, bem como quando comparado aos resultados do estudo desenvolvido por Brandão (1999).

Considerando a escassez de estudos científicos sobre gestão por competências, principalmente no ramo de cooperativas, recomenda-se a realização de novos estudos sobre o tema. Pesquisas dedicadas, por exemplo, à: Identificação de competências essenciais para colaboradores de 
cooperativas de crédito. Identificação de indicadores que demonstrem o ganho social proporcionado aos colaboradores de cooperativas de crédito, pela gestão por competências.

Identificação de competências necessárias para as cooperativas interagirem com associados/clientes por meio de redes de relacionamento digitais. Identificação das dificuldades quanto à implantação de um sistema de gestão por competências em cooperativas de crédito.

Acredita-se que os resultados obtidos neste estudo possam contribuir para o aperfeiçoamento do modelo de gestão praticado pela cooperativa "Gama", completando e atualizando a relação de conhecimentos, habilidades e atitudes ideais para os colaboradores desta instituição. Esses resultados, se combinados a estudos complementares, podem dar origem a diversas ações, como treinamento e desenvolvimento, recrutamento e seleção consolidando, desta forma, iniciativas para um atendimento de qualidade. Dessa forma, a empresa pode desenvolver uma vantagem competitiva, assegurando um diferencial no segmento de mercado em que atua.

\section{Referências}

BITENCOURT, Cláudia Cristina. A gestão das competências gerenciais: a contribuição da aprendizagem organizacional. 2001. 313f. Tese (Doutorado em Administração) - Programa de Pós-Graduação em Administração, Universidade Federal do Rio Grande do Sul, Porto Alegre. Disponível em: http://fortium.edu.br/blog/valeria_martins/files/2010/10/aprendizagemorganizacional.pdf. Acesso em: 9 mai. 2011.

BRANDÃO, Hugo Pena. Gestão baseada nas competências: um estudo sobre competências profissionais na indústria bancária. 1999. 170f. Dissertação (Mestrado em Administração) - Departamento de Administração, Universidade de Brasília, Brasília (DF).

BRANDÃO, Hugo Pena; GUIMARÃES, Tomás de Aquino. Gestão de competências e gestão de desempenho: tecnologias distintas ou instrumento de um mesmo construto?. Revista de Administração de

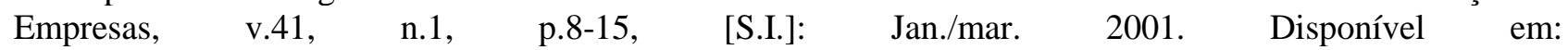
http://fortium.edu.br/blog/valeria_martins/files/2010/10/Compet\%C3\%AAnciaedesempenho.pdf. Acesso em: 06 mar. 2011.

BRANDÃO, Hugo Pena; BAHRY, Carla Patrícia. Gestão por competências: métodos e técnicas para mapeamento de competências. Revista do Serviço Público Brasília, v.56, n.2, p.179-194, [S.I.]: Abr./Jun. 2005. Disponível em: http://ieprev.com.br/UserFiles/File/RSP56_2.pdf\#page=57. Acesso em: 6 mar. 2011.

CARBONE, Pedro Paulo; RUFATTO JUNIOR, Edgard. Oficina: O sistema de desenvolvimento profissional e de gestão por competências do banco do Brasil. Ministério do desenvolvimento, indústria e comércio exterior. IS.I.]: 2006, site. http://www.educor.desenvolvimento.gov.br/public/arquivo/arq1229429519.pdf. Acesso em: 5 jun. de 2011.

DUTRA, Joel Souza. Gestão de pessoas por competências: um novo modelo de gestão ou modismo. Workshop gestão de competências nas organizações. 2. 2003, São Leopoldo, Anais, CD-ROM.

EXPRESSÃO DO COOPERATIVISMO GAÚCHO 2018. Sistema OCERGS-SESCOOP/RS. Disponível em: http://www.sescooprs.coop.br/app/uploads/2018/07/sescooprs-expressao-cooperativismo-gaucho2018.pdf. Acesso em: 02 maio. 2019.

FISCHER, André Luiz. Gestão por competências. 2. ed. São Paulo: Gente, 2001.

FLEURY, Afonso Carlos Correa; FLEURY, Maria Tereza Leme. Construindo o conceito de competência. Revista de Administração Contemporânea, Edição Especial, p. 183-196, [S.I.]: 2001. Disponível em: http://www.anpad.org.br/rac/vol_05/dwn/rac-v5-edesp-mtf.pdf. Acesso em: 8 mai. 2011. 
HIPÓLITO, José Antônio Monteiro. Administração salarial: a remuneração por competências como diferencial competitivo. São Paulo: Atlas, 2001.

MAÑAS, Antônio Vico. Gestão empresarial. 2. ed. São Paulo: Atlas, 2007.

PRAHALAD, Coimbatore Krishnarao. Reexame de competências. Revista HSM management, [S.I.]: nov./dez. 1999. Disponível em: http://www.mettodo.com.br/pdf/Reexame\%20de\%20Competencias.pdf. Acesso em: 2 jun. 2011.

RESENDE, Enio. O livro das competências: desenvolvimento das competências: a melhor auto ajuda para pessoas, organizações e sociedade. Rio de Janeiro: Qualitymark, 2000.

ROESCH, Sylvia Maria Azevedo. Projetos de estágio e de pesquisa em administração: guia para estágios, trabalhos e conclusão, dissertações e estudo de caso. 3. ed. São Paulo: Atlas, 2009.

RUAS, Roberto Lima. Gestão por competências: Uma contribuição à estratégia das organizações. Workshop gestão de competências nas organizações. 2. ed. 2003, São Leopoldo, Anais, CD-ROM.

RUAS, Roberto Lima et al. Aprendizagem organizacional e competências: os novos horizontes da gestão. Porto Alegre; Bookman, 2005.

SARSUR, Amyra Moyses; Gestão por competência: a percepção de ganho social do trabalhador. 2007. 271f. Dissertação (doutorado) - Universidade de São Paulo, São Paulo. Disponível em: http://www.teses.usp.br/teses/disponiveis/12/12139/tde-05072007-115400/publico/AmyraPDFTese.pdf.

Acesso em: 12 maio de 2011.

TRASATTI, Sidney Roberto; COSTA, Maria Inês. Gestão de RH por competência e a empregabilidade. 4. ed. São Paulo: Papirus, 2010.

ZARIFIAN, Philippe. Objetivo competência: por uma nova lógica. São Paulo; Atlas, 2001. 